\title{
Hungarian focus is not exhausted
}

\author{
Edgar Onea \\ University of Stuttgart University of Texas at Austin
}

\section{Introduction}

According to the received view, if in Hungarian a focused expression appears in the immediately pre-verbal position as in (1) it is interpreted exhaustively, i.e. as if it were in the scope of an exclusive like 'only', while if it appears somewhere else as in (2) this exhaustiveness effect is not available (Szabolcsi 1981).

(1) Péter MARIT csókolta meg.

Peter Mary.ACC kissed PRF

'Peter kissed Mary (and no one else).'

(2) Péter meg-csókolta MARIT.

Peter PRF-kissed Mary.ACC

'Peter kissed Mary (and possibly someone else as well).'

This observation has lead to the more general distinction between identificational focus which is moved from its initial argument position and exhaustive and information focus which appears in its argumenta position and is not (necessarily) exhaustive (É. Kiss 1998). E.g. English it-clefts have been argued to be instances of identificational focus while prosodic focus in English is thought of as an instance of information focus.

The crucial aspect of this distinction that we are discussing in this paper is the claim of Szabolcsi (1981), É. Kiss (1998, 2007), Horváth (2006) and others that an immediately pre-verbal focus in Hungarian is semantically exhaustive, i.e. the exhaustiveness of the immediately pre-verbal focus is part of the truth conditions of the corresponding sentences. We argue against this conclusion. We show based on experimental results that while immediately pre-verbal focus in Hungarian leads to stronger exhaustivity inferences than e.g. prosodic focus in German, this effect is unlikely to be a truth conditional one.

In addition we present a new observation regarding the interaction between verbal particles and focus interpretation in Hungarian, an observation that is methodologically significant since it shows that a basic assumption underlying much prior

This research has partly been supported at the University of Stuttgart by collaborative research center (SFB) 732 Incremental specification in context, project C2 Case and referential context funded by the German Science Foundation (DFG), and at the University of Texas by NSF grants BCS- 0952862 Semantics and Pragmatics of Projective Meaning across Languages, as well as by NSF BCS-0904913, BAA DCHC-BAA-000101, and by the NYCT TeXIT project. (n.b. An omission in these acknowledgments was corrected after the original publication, on August 8, 2011.) 
empirical work is unsound. Briefly, verbal particles in Hungarian are perfective, and highlight the end state associated with a telic verb. Such particles are standardly analyzed as taking a default unmarked position immediately before the verb, phonologically combining with the verb into a single unit as in (2). But particles do not always remain in pre-verbal position: the reason particles are used as a diagnostic for the presence of an exhaustive focus is that when a focused item is present in a pre-verbal position, the particle appears post-verbally as in (1).

Now we come to the crucial assumption that has been made in prior literature: in using particles as a diagnostic while studying exhaustiveness effects of focus position, it is tacitly assumed that the presence of the particle is not directly relevant to exhaustiveness, and thus that effects observed using examples with particle-verb combinations carry over to sentences which lack particles. Our experimental results show, however, that immediately pre-verbal focus in Hungarian is interpreted more exhaustively if a verbal particle is present. Thus much of the literature purporting to provide generalizations regarding exhaustivity of Hungarian pre-verbal focus position is misleading, since it is based on a (large) subset of constructions which are not fully representative as regards exactly the property under study.

Building on the experimental findings we provide a pragmatic analysis for the exhaustiveness effect associated with immediately pre-verbal focus in Hungarian. The crucial elements of our analysis are the hypothesis that immediately preverbal focus is grammatically constrained to be a question-answering constituent and the observation that answers to questions are generally interpreted as complete answers. In addition we suggest a hypothesis which explains how the aspectual properties of pre-verbal particles in Hungarian can contribute to an even stronger pragmatic exhaustification tendency.

The structure of this paper is as follows: in the next section we present the general exhaustiveness argument and the kinds of tests that have been used to show that immediately pre-verbal focus in Hungarian is semantically exhaustive and we point out some shortcomings of these tests. Then we present the experimental design and the results of the experiments which show that Hungarian focus is only pragmatically exhaustive, as well as discussing our new observations regarding the interaction between focus interpretation and the presence vs. absence of verbal particles. We then discuss our proposed model, and summarize the main conclusions.

\section{The exhaustiveness discussion}

In this section we first provide a brief overview of some of the main reasons scholars have claimed that immediately pre-verbal focus in Hungarian is semantically exhaustive. We discuss the limitations of the invoked arguments with regard to the crucial question, whether the exhaustiveness effect associated with immediately pre-verbal focus in Hungarian is semantic or pragmatic, and also present some well known counter arguments against semantic exhaustification. 
The first and probably the most important piece of evidence for the exhaustive nature of immediately pre-verbal focus in Hungarian is the intuition that if we compare (1) and (2) the former is clearly more exhaustive than the latter in the sense specified in the translation. This intuition is shared by many scholars that are native speakers of Hungarian. We accept this intuiton, and the experimental data we present in Section 3 confirm it. However, this intuition only shows that immediately pre-verbal focus in Hungarian is interpreted as being more exhaustive than other constituents in Hungarian, but does not reveal anything about the compositional details and the semantic or pragmatic nature of the exhaustiveness effect.

The second piece of evidence for exhaustiveness of pre-verbal focus is provided by Szabolcsi (1981). According to her, the sentence in (3) is acceptable in Hungarian, whereas if the pre-verbally focused expression Peter were not interpreted exhaustively, the sentence ought to be a contradiction and hence not acceptable. Note that Szabolcsi presents this not only as an argument for exhaustiveness, but also for the semantic nature of this effect, on the basis of the interaction with negation.

(3) Nem PÉTER aludt a padlón, hanem Péter és Pál

Not Peter slept the floor-on but Peter and Paul

'It wasn't Peter who slept on the floor, but Peter and Paul.'

Onea (2007) has argued that under specific conditions such a sentence is also felicitous in languages in which a strict exhaustive focus interpretation has never been claimed: in particular such sentences are acceptable in German if they refer to a singular event in which Peter and Paul are participating together. In these cases exhaustiveness would be coded independently of focus. Such event related features have recently been argued to be responsible for exhaustiveness inferences in Kratzer (2009) as well. Moreover, Onea (2007) argues that this also applies to Hungarian, hence (4) is predicted to be clearly more acceptable in Hungarian than (3). This intuition, although shared by our native speaker consultants, has been challenged by Anna Szabolcsi (p.c.), so this remains an important, unsettled data question.

(4) Nem PÉTER tartja az asztalt, hanem Péter és Pál

Not Peter holds the table but Peter and Paul

'It isn't Peter who is holding the table, but Peter and Paul.'

Even under the assumption that the empirical basis of the second exhaustiveness argument is sound (which is not clear at all), the argument itself is still incomplete. The reason for this is the existence of perfectly acceptable sentences like (5) what Horn (1985) calls metalinguistic negation. Unless it can be shown that (3) is not an instance of metalinguistic negation, the acceptability of (3) has little relevance for the discussion. As it turns out, this is no easy task: a sentence like (3) would typically be used to deny an utterance claiming that Peter sleeps on the floor, but it is by no means clear that the denial has to rest on semantic grounds. ${ }^{1}$

\footnotetext{
${ }^{1}$ Note that the assumption that (3) is an instance of metalinguistic negation is compatible with
} 
(5) You didn't drink a GLASS of WINE last night, you drank a glass of wine, three margaritas, and almost half a bottle of my favorite 12 year old, oak cask-conditioned, single malt WHISkey!

The third piece of evidence for exhaustiveness comes from the distribution of pre-verbal quantifiers and verbal particles. It has been already pointed out above that verbal particles are usually pre-verbal but that if immediately pre-verbal focus is present they appear post-verbally. Now this property is used as a diagnostic in making another distributional observation, which concerns a contrast between quantifiers like kevés ('few') and minden ('every'). Examples (6) and (7) illustrates the fact that while nominal phrases headed by kevés ('few') always appear in preverbal focus position, those headed by minden ('every') can never appear in preverbal focus position. This is taken to be an effect of exhaustiveness. Thus, in the examples, kevés ('few') sets an upper bound on how many girls were kissed, and hence may be thought of as inherently exhaustive, while minden ('every') suggests that there is no non-trivial upper bound on the number of girls who were kissed, and so is inherently non-exhaustive. In addition, if a $\operatorname{csak}$ ('only')-phrase is present in a sentence, it must appear in the immediately pre-verbal position, as shown in (8). ${ }^{2}$

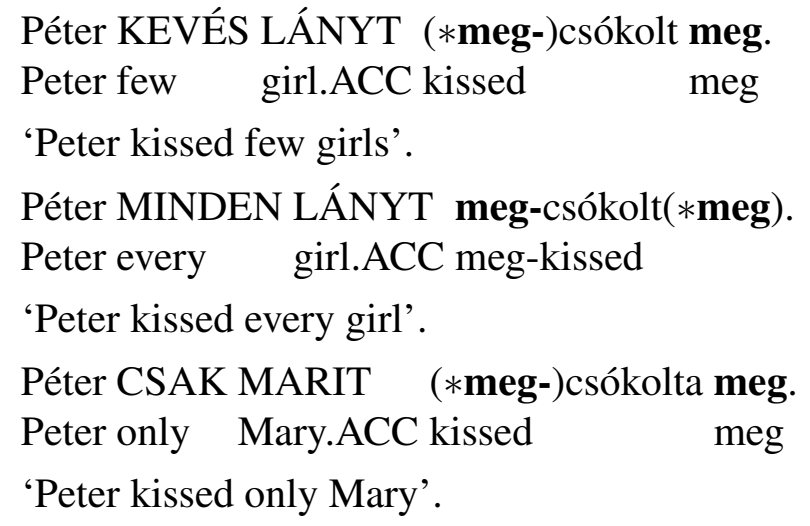

Summarizing, the data (6)-(9) seems to show that expressions which are in some sense inherently exhaustive must appear in pre-verbal focus position, while expressions which in some sense are inherently non-exhaustive cannot appear there, and this has been taken to imply that pre-verbal focus position is itself inherently associated with exhaustivity.

While the argument may indeed show that there is some kind of connection between exhaustification and the immediately pre-verbal position, it is not clear to us how this implies that pre-verbal focus is semantically exhaustive. What does follow from the fact that kevés-phrases can only appear in the focus position in Hungarian? One could argue that kevés-phrases must appear in the immediately pre-verbal position because they have an exhaustiveness feature, but it is clear that

the observation that such sentences get more acceptable if Peter and Paul are participants of the same event, since in this case mentioning the formerly unmentioned participant appears more natural in the first place.

${ }^{2}$ Excepted from this generalization are cases in which some other constituent appears in the immediately pre-verbal position. This exception applies both to csak- and kevés-phrases. 
Hungarian kevés is very similar in meaning to English few and it doesn't seem to be the case that Hungarian kevés actually means only few. In fact there is a clear contrast between kevés and csak kevés ('only few') in Hungarian. Hence, it is not likely that the lexical meaning of kevés includes an exhaustiveness feature. The argument is even more puzzling as one considers (8): if Hungarian csak is lexically exhaustive, why would it need to move to an exhaustificational position? In fact, what would we gain from applying some exhaustificational operator to something that is already lexically exhaustive. Finally, the assumption that the immediately preverbal position hosts an exhaustification operation could perhaps explain why minden-phrases cannot appear in the immediately pre-verbal position, but clearly, this leads to over-generation. Consider for instance the quantifier sok ('many'), which in a pre-verbal position is compatible both with pre-verbal and post-verbal verbal particles as shown in (9). Crucially, there is no semantic contrast here such that in the one case sok were interpreted as contrasting to minden or some set that contains more then the number elements one would callsok (which would be an exhaustive interpretation predicted for (10b)) while in the other case sok were interpreted as contrasting with kevés or something else (which would be the non-exhaustive interpretation predicted for (10a)). In fact, the only contrast available seems to be that (10b) is conceived as a direct answer to the question in (10) whereas (10a) is not (although it may be seen as part of answer). In fact, if we assume that a mindenphrase is not a possible direct answer to a how-many-question while kevés is, the contrast between (6) and (9) is explained without referring to exhaustiveness at all.

\section{Péter SOK LÁNYT (meg-)csókolt (meg).}

Peter many girl.ACC kissed meg

'Peter kissed many girls'.

Hány lányt csókolta meg Péter?

How-many girl.ACC kissed PRF Peter

How many girls did Peter kiss?

a. Péter SOK LÁNYT (meg-)csókolt Peter many girl.ACC PRF-kissed

'Peter kissed many girls. (So dont ask for a number!)

b. Péter SOK LÁNYT csókolt meg.

Peter.ACC many girl PRF-kissed

'MANY GIRLS kissed Peter. (And not just a few.)

The claim that immediately pre-verbal focus in Hungarian is semantically exhaustive has been questioned in the literature before. Wedgwood (2005), based on an example going back to Horn, provides an example showing that at least there is no covert only in the pre-verbal position in Hungarian. If there were a covert only in the pre-verbal position, one would expect not only (11) but also (12) to be acceptable in Hungarian, which however is not the case. 
(11) Azt tudtam, hogy Mari megevett egy pizzát, de most vettem that knew.I.SG that Mary ate a pizza.ACC but now took.I.SG észre, hogy csak EGY PIZZÁT evett meg. notice that only a pizza.ACC ate PRF

'I knew that Mary ate a pizza, but I have just noticed that it was only A PIZZA she ate.

(12) ??Azt tudtam, hogy Mari megevett egy pizzát, de most vettem that knew.I.SG that Mary ate a pizza.ACC but now took.I.SG észre, hogy EGY PIZZÁT evett meg. notice that a pizza.ACC ate PRF

Intended reading: 'I knew that Mary ate a pizza, but I have just noticed that it was (only) a PIZZA she ate.

Another kind of counter-evidence for the exhaustivity operator approach is based on naturally occurring examples like (13) provided by a corpus study of Wedgwood et al. (2006). The argument is, that if immediately pre-verbal focus were to be semantically exhaustive, (13) should be a contradiction. Instead the sentence is completely acceptable and has no nonsensical flavor.

Péter többek között MARIT csókolta meg. Peter among others Mary.ACC kissed PRF

'Peter kissed MARY, among others

\section{Experimental evidence against semantic exhaustiveness}

In the previous section we introduced the standard arguments in favor of the semantically exhaustive nature of immediately pre-verbal focus in Hungarian, and discussed their limitations. In order to settle the question of whether Hungarian focus is indeed semantically exhaustive we conducted a series of experiments that clearly show that on the one hand immediately pre-verbal focus in Hungarian is more exhaustive than prosodic focus in languages like German but on the other hand clearly less exhaustive than sentences containing exclusives like only, which we take to be clearly conventionally exhaustive.

In this section we first present the theoretical assumptions behind our experimental approach, followed by the experimental setup and results of both conducted experiments.

\subsection{Aims and methodology}

The series of experiments conducted attempt to settle the question whether exhaustiveness effects associated with Hungarian focus are pragmatic or semantic in na- 
ture. The experiments are based on the following two assumptions: ${ }^{3}$

1. We assume that if exhaustiveness were a truth conditional effect conventionally associated with immediately pre-verbal focus, and if evidence is given that the exhaustiveness inference is false, then people would contradict a sentence containing immediately pre-verbal focus.

2. Moreover, if pre-verbal focus conveys the same truth-conditional information as an explicit exhaustificational operator (like only), then we would expect people to contradict exhaustiveness (i) inferences triggered by pre-verbal focus and (ii) those triggered by explicit exhaustiveness operators in similar conditions and at a similar rate.

There are different methods which have been used in the literature for testing whether subjects judge sentences as true or false in a given situation, e.g. different kinds of truth value judgement tests. However, the paradigm of directly asking whether a sentence is true or not in a given situation is potentially problematic here. One of the problems is that pre-verbal focus is clearly a type of information structural marking. Information structure is related to discourse context, and so in experimentally testing the effects of information structural marking, judgments of truth or falsity of a single sentence are highly unnatural. It would be more natural to embed the target sentence within a discourse, and to allow the subject to perform a task which seems appropriate within a normal conversation. One aspect of conversation that is naturally correlated to judgments of truth and falsity in discourse is agreement vs. disagreement. We will assume that given a situation in which the participant has knowledge about the situation in the world, the question whether the participant judges an utterance as true or false in that situation might be settled by looking at the extent to which a participant expresses agreement or disagreement, given a forced choice.

Under this assumption, if speakers of a language tend to contradict a sentence, one can conclude that there is some kind of inherent incompatibility between the meaning of the sentence and the situation. This kind of inherent incompatibility can be seen as an incompatibility between the truth conditional content of the sentence and the situation. Of course, there may be other reasons to disagree with a sentence, but we do not need to worry about this, since in order to falsify the claim that immediately pre-verbal focus in Hungarian is semantically exhaustive we only need to look at cases in which people accept a sentence containing immediately pre-verbal focus even though the exhaustiveness inference is known to be false.

Of course, the reasons not to contradict (hence, to accept) a sentence may also be various, stretching from lack of interest in achieving a genuine common ground to reasons of politeness, but if there is reason to believe that people do contradict false sentences regularly in a certain experimental setup then these considerations may be neglected. For this reason we use sentences containing an exclusive

\footnotetext{
${ }^{3}$ It should be clear that we are not able to prove these assumptions in this paper. Further research is necessary to confirm or falsify them.
} 
like only for comparison. Suppose that participants regularly contradict sentences containing an explicit exclusive in some context, but fail to contradict similar sentences containing immediately pre-verbal focus without only: this, we claim, would constitute evidence that immediately pre-verbal focus is not semantically exhaustive in the way that only is.

In addition we assume that contradicting an utterance is an extreme measure in communication at least as far as social normative aspects for Hungarian and many other languages are concerned. There may be a whole array of disagreement or discontent regarding an utterance for which an overt contradiction may generally not be chosen. Assume for instance that an utterance is misleading or not relevant for the tasks of the communication. In this case the hearer may choose not to contradict the sentence but rather to give a yes, but type of answer, which on the one hand signals his displeasure but on the other hand avoids contradiction. We further assume that overt contradiction (no) is reserved for more serious types of disagreement. Hence, if indeed, the exhaustiveness effect associated with immediately pre-verbal focus in Hungarian is pragmatic as opposed to semantic, we would expect that people will more often react by disagreeing but not contradicting.

\subsection{The first experiment}

In the first experiment native speakers of Hungarian were confronted with isolated spoken sentences involving pre-verbal focus on the subject like (14), csak ('only') as in (15), or default intonation as in (16). In each case they were confronted with visual stimuli like that in Figure 1:

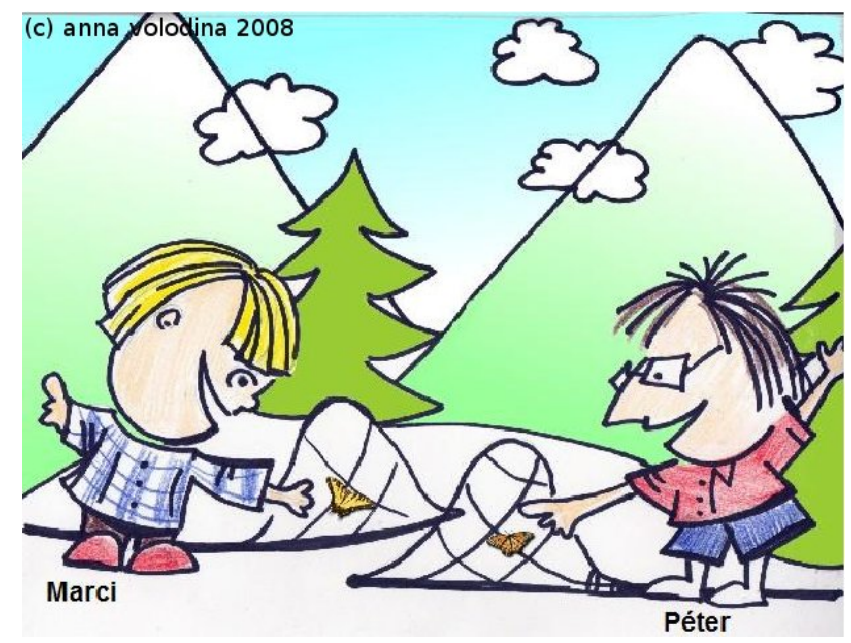

Figure 1: Sample stimulus.

(14) MARCI fogott meg egy lepkét. Marci caught PRT a butterfly

'Marci caught a butterfly' 
Csak MARCI fogott meg egy lepkét.

Only Marci caught PRT a butterfly

'Only Marci caught a butterfly'

(16) Marci meg-fogott egy lepkét.

Marci PRT caught a butterfly

'Marci caught a butterfly'

The task of the participants was to choose from three possible responses incorporating different levels of acceptance. For the example above, the answers were Hungarian equivalents of the three sentences in (17). We assume that the more exhaustive a sentence is judged the more likely it is that people will choose $(17 b)$ or $(17 c)$.

(17) a. Yes, and Peter caught a butterfly too.

b. Yes, but Peter caught a butterfly too.

c. No, Peter caught a butterfly too.

Note that the pictorial stimulus shows not only that the subject of the spoken sentence has the property asserted by the sentence, but also that there is at least one additional person who has the same property. Hence, sentences in the first condition, which we will refer to as only-sentences, are false, sentences in the third condition, which we will refer to as default sentences are true but possibly pragmatically misleading, and sentences in the second condition, which we will refer to as focus-sentences, are false or misleading depending on whether the exhaustiveness feature is part of the truth conditional content or not.

Given this setup, if immediately pre-verbal focus in Hungarian is semantically exhaustive, we expect the results for focus-sentences to pattern like the onlysentences, whereas if Hungarian focus is not semantically exhaustive, we expect the results for focus-sentences to pattern more similarly to the default sentences.

In the experiment, 8 lexicalizations for each condition were used. The experimental software ${ }^{4}$ randomly chose 2 stimuli for each condition, a total of 6 stimuli for each participant, as well as 6 control sentences and 13 fillers. This total set of 25 stimuli was presented in a random order.

There were 22 participants aged 17-65; of these, 12 participated in the experiment under supervision in Budapest, and 10 without supervision over the web. There were no noticeable differences between the answers of these groups. We excluded 2 supervised and 1 unsupervised participant from the results because of mistakes in the control stimuli, and hence the results reported below are based on 19 participants. $^{5}$

For comparison we repeated exactly the same experiment in German, but using appropriately translated experimental items. The major difference was that in

\footnotetext{
${ }^{4}$ We used our own custom-built experimental software. The source code of the experimental software is available from $<$ http://www. ilg.uni-stuttgart. de/mitarbeiter/onea .

${ }^{5}$ Note that due to a typographical error in one of the stimuli noticed only after the experiment, we also needed to exclude one lexicalization.
} 
German there is no specific focus position, pre-verbal or otherwise. Instead focus intonation (A-accent) on the subject was used in analogy to the focus-sentences in Hungarian, and default intonation without an A-accent on the objects was used as an analogy to the normal sentences in Hungarian. So in the results and discussion below, pre-verbal focus in Hungarian is being compared to prosodic focus in German. The participants in the German experiment were 12 undergraduate students, but even with these low numbers a very clear difference to the Hungarian data could be shown. ${ }^{6}$

\subsection{Results of the first experiment}

The experimental results clearly show first that immediately pre-verbal focus in Hungarian is significantly less likely to be contradicted for not being exhaustive than only-sentences, and second that the exhaustiveness effect associated with preverbal focus in Hungarian is much clearer than the exhaustiveness effect associated with prosodic focus in German.

The detailed results of the Hungarian experiment are shown in the Figure 2. The figure clearly shows that there is a pre-verbal focus effect regarding the tendency to contradict sentences that are not exhaustive as compared to the default case, but this effect is not comparable to the effect of an explicit exclusive. If the exclusive is present nearly all answers were no-answers, while in the focus case yes but answers were the most common. A statistical analysis shows that this difference is significant $\left(\chi^{2}(2)=20.17, p<0.01\right)$.

There is a very clearly observable effect of pre-verbal focus as well, since most people did not simply accept the sentences but gave yes but or no answers in the pre-verbal focus condition, while more than half of the subjects gave a yes and answer in the default case. This effect is not statistically significant in the first experiment because of the low quantity of relevant data-points, but is consistent with the hypothesis that pre-verbal focus has some effect on exhaustiveness. ${ }^{7}$

In Figure 3 the analogous results for German are presented. The figure shows that in German the difference between the only condition and the focus condition is just as clear as in Hungarian. Significantly less clear is the effect of focus on exhaustiveness. The data, though sparse, suggest that the exhaustiveness effect associated with prosodic focus in German is weaker than the exhaustiveness effect associated with pre-verbal focus in Hungarian.

In Figure 4, the Hungarian and German results are compared. In order to

\footnotetext{
${ }^{6}$ While this experiment can only be judged as a pilot experiment due to the low number of participants, we have since conducted three follow-up experiments for Hungarian and one followup experiment in German. These experiments all used larger numbers of participants (up to 119), and more lexicalizations. Our preliminary analysis of these results shows that they confirm all the findings of the experiments reported in this paper. We hope to report on the the results of the followup experiments in the near future.

${ }^{7}$ Both tendencies have been confirmed by follow-up experiments. Importantly, in the follow-up experiments, the relative number of no answers in the focus-condition is somewhat lower than in this pilot experiment.
} 

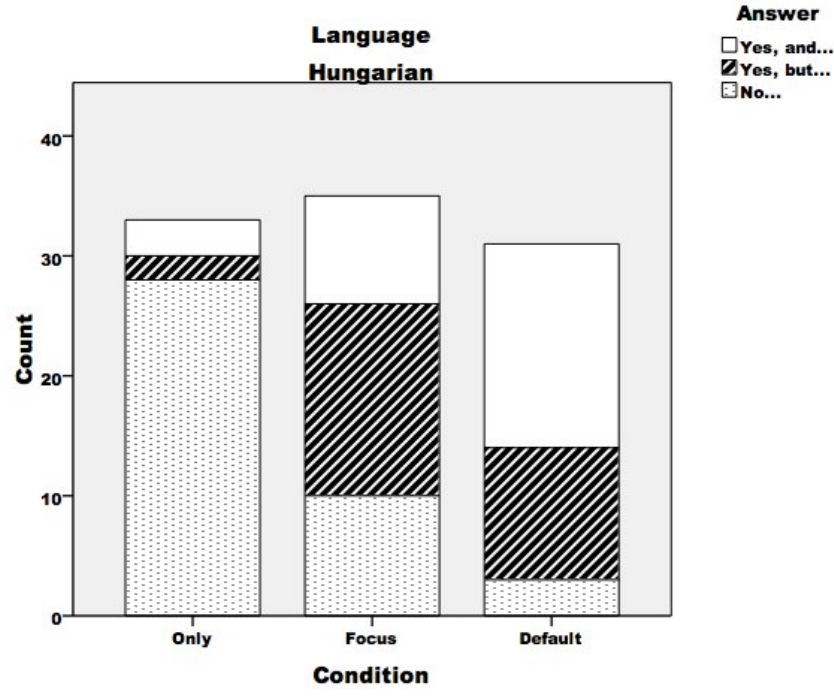

ZNo...

Figure 2: Results of the first experiment for Hungarian in absolute numbers.
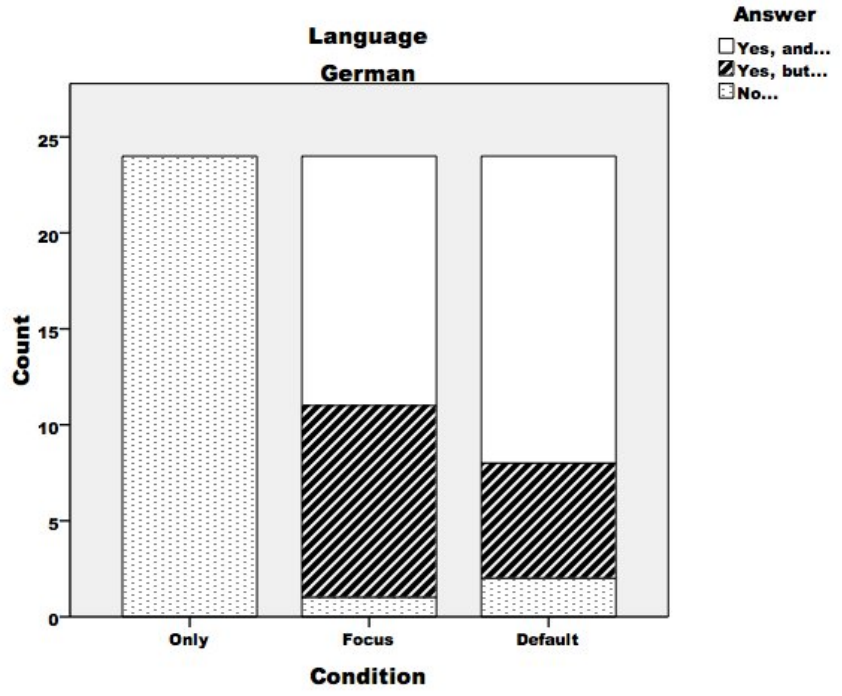

GNo...

Figure 3: Results of the first experiment for German in absolute numbers.

make the comparison more convenient, in this figure we reproduced the relative of the three different kind of answers relative to the total number of answers that were given for a particular condition in a given language.

The results are summarized in a somewhat more intuitive way in Figure 5 by means of an average number that we obtained by assigning no-answers the value 2 , yes but answers the value 1 and yes and answers the numeric value 0 .

The average number gained this way can be considered a rough exhaustive- 


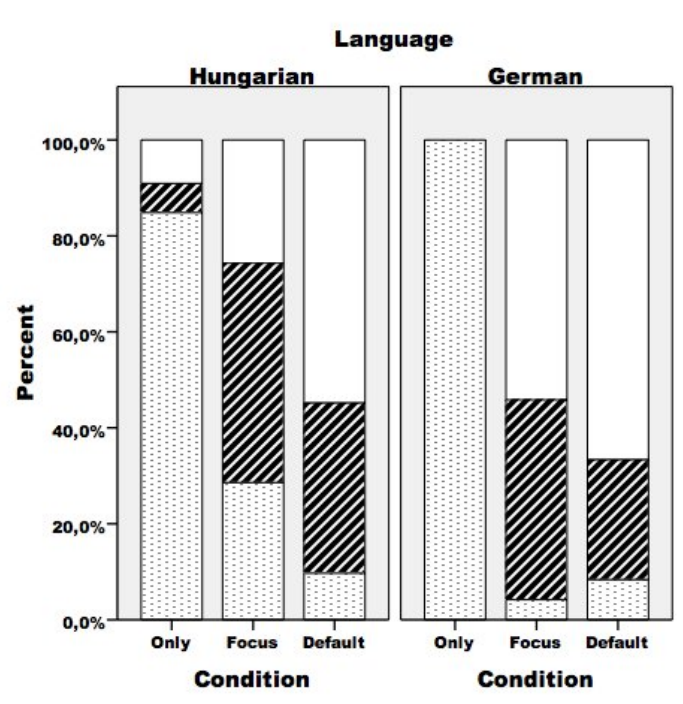

Answer
$\square$ Yes, and...
ZYes, but...
ENo...

Figure 4: Results of the first experiment for Hungarian and German in percentage.

ness measure, the higher the number, the more exhaustive the sentence seems to be judged by the experiment participants. Here, the difference in exhaustiveness between German and Hungarian focus sentences (where the Hungarian sentence has a pre-verbal focus) is much clearer, hence it seems that pre-verbal foci in Hungarian are interpreted more exhaustively than prosodic foci in German. But again, this first experiment does not enable us to draw a firm conclusion on this issue: the difference between Hungarian pre-verbal focus and German prosodic focus is only a tendency extrapolated from a relatively small number of data points.

While the results of the first experiment clearly indicate that immediately pre-verbal focus in Hungarian is not semantically exhaustive, the results are compatible with the weaker claim that immediately pre-verbal focus in Hungarian is in some way special. So to this extent our results provide limited support for Szabolcsi, É. Kiss and others, all of whom maintain that Hungarian pre-verbal focus is more exhaustive than prosodic focus in many other languages, e.g. German and English. 


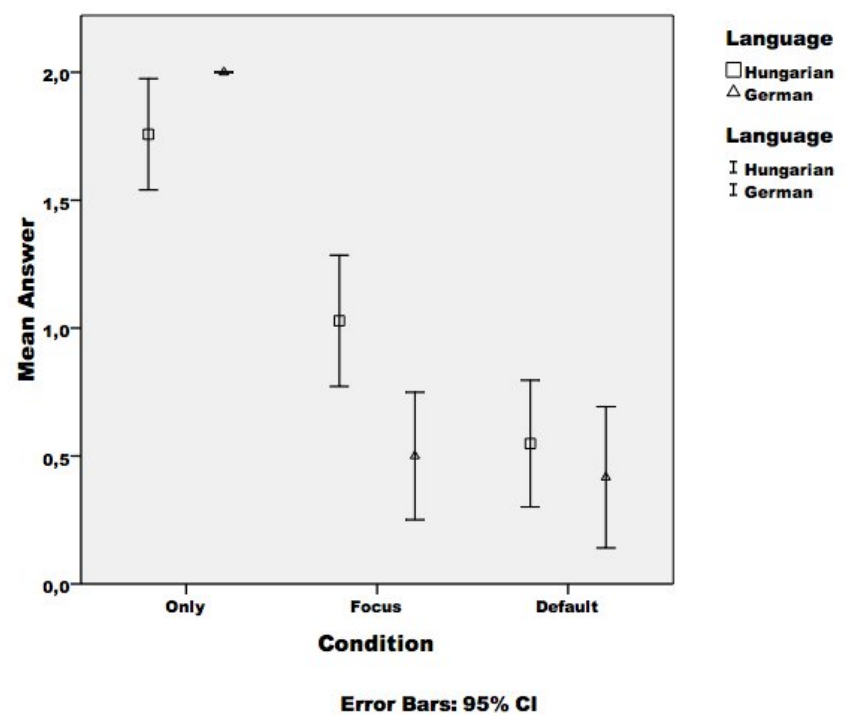

Figure 5: Compared results between Hungarian and German in average values.

\subsection{Second experiment}

The second experiment should be understood against the backdrop of the explanatory account we have in mind. We suggest that exhaustiveness inferences can be associated with specific discourse functions, and that Hungarian pre-verbal focus is more narrowly specialized for such functions than is German prosodic focus. Specifically, we hypothesize that:

1. The exhaustiveness inference arises pragmatically from an association between the pre-verbal focus position in Hungarian and the answering constituent for a wh-question under discussion, in the sense of Roberts (1996) and Beaver and Clark (2008).

2. Immediately pre-verbal focus in Hungarian is always the answering constituent to a (possibly implicit) question under discussion.

If these hypotheses are correct, the prediction is that adding an appropriate $w h$-question would not increase the level of exhaustiveness for Hungarian focus sentences. However, since German prosodic focus can perform a number of functions (e.g. expressing contrast), making the question explicit would narrow down the functions that a particular token of German prosodic focus could have, and so would be predicted to increase the exhaustiveness level of German sentences.

In the second experiment, then, we added a wh-question to the experimental design, such that the participants saw the visual stimulus accompanied by a wh-question such that the focused constituent in the audio-stimulus delivered the answer to it. This time 53 subjects participated in the Hungarian experiment and 74 in the German counterpart. 


\subsection{Results of the second experiment}

The results of the second experiment are presented in Figure $6 .^{8}$ In the first place, these results support the main result of the first experiment: Hungarian pre-verbal focus position is not semantically exhaustive, since speakers tend not to directly deny utterances with pre-verbal foci when the associated exhaustivity claim is false. Our results also show also that the effect of the question under discussion is different for German and Hungarian. Although only part of the stimuli were identical to those from the first experiment, so that the comparison between the experiments has only a suggestive power, still it seems clear that for Hungarian the exhaustiveness level of pre-verbal focus decreased and actually equals the exhaustiveness level of German sentences.

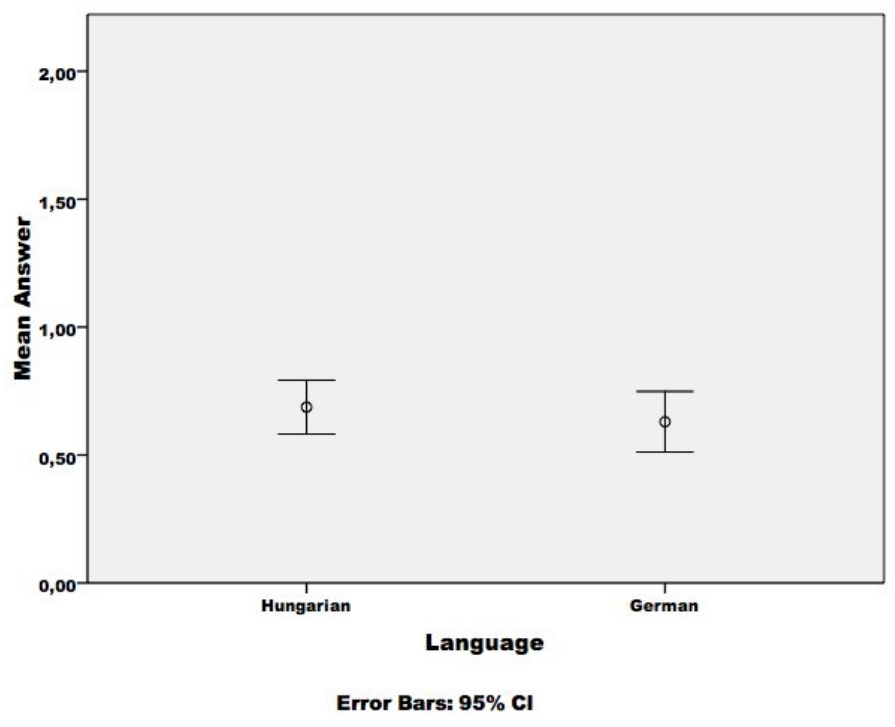

Figure 6: Comparison of Hungarian and German focus following explicit questions.

If in Hungarian the immediate pre-verbal position were not a grammaticalized position for the answering constituent, it would be hard to explain why the presence of a contextual question did not contribute to a higher level of exhaustiveness, as it did in German. Note, that in German the increase in exhaustiveness is very clear, and visible in a comparison of the Focus conditions in Figures 5 and 6. In isolation, answers scored below 0.5 on average in the first experiment, but when wh-questions were introduced in the second experiment, the average score is significantly higher than 0.5 .

Summing up, and although at this stage of our research they are still incomplete, our experimental results, clearly show that:

\footnotetext{
${ }^{8} \mathrm{We}$ omit discussion here of results for the default condition in Hungarian and German. These results support the (uncontroversial) claim that Hungarian pre-verbal focus position is more exhaustive than Hungarian default word-order.
} 
1. Hungarian focus is not semantically exhaustive, i.e. the exhaustiveness inference for pre-verbal focus in Hungarian is not part of the truth conditions of the corresponding sentences, and

2. Pre-verbal focus in Hungarian is more exhaustive than prosodic focus in German in isolation, but this difference disappears as soon as contextual questions are introduced to which the stimulus is an answer.

\subsection{Further results: verbal particles and exhaustiveness}

The experimental stimuli in both experiments involved both verbs with and without pre-verbal particles. At a closer look, it turns out that the focus-sentences in Hungarian were judged to be significantly more exhaustive if a verbal prefix was present. Hence either the complex verb, or the prefix itself, seems to play a role in inducing exhaustification.

In Figure 7 the results for the focus-condition in Hungarian in the first experiment are split up depending on the presence [+prefix] or absence [-prefix] of verbal prefixes. ${ }^{9}$

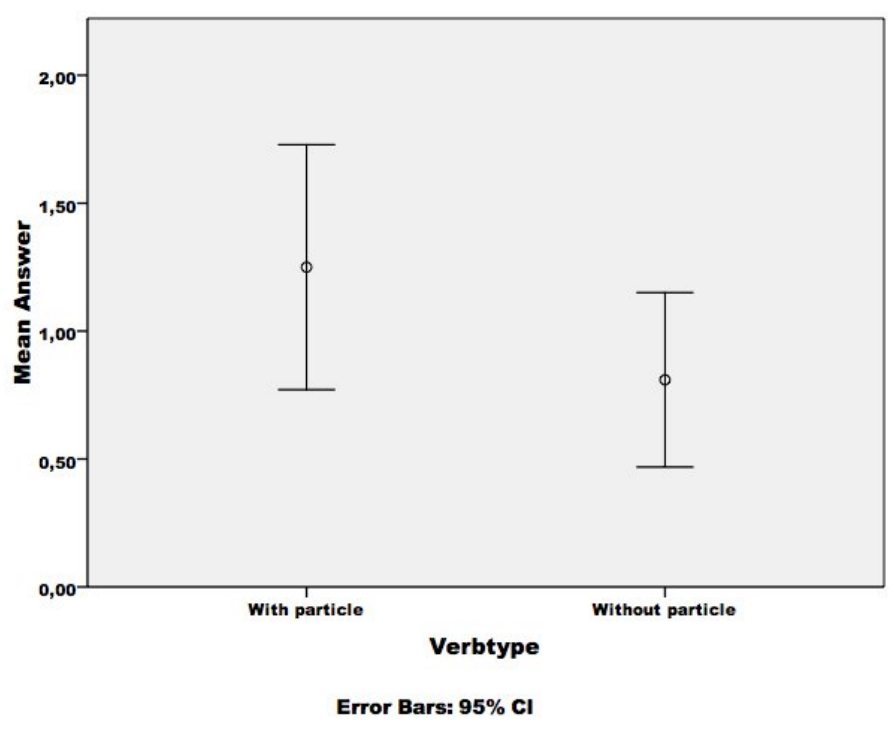

Figure 7: Comparison between verbs with and without particles.

A simple explanation for these findings could be that in the case of simple verbs the subjects did not realize that an instance of immediately pre-verbal focus was present, i.e. they parsed the sentence with a structure other than the one

\footnotetext{
${ }^{9}$ Unfortunately the low number of data points does not allow a safe generalization. In a number of follow-up experiments the same tendency has become clear, and is statistically significant, although the effect is strong only when no contextual question is present.
} 
intended, ignoring the very strong acoustic effects found with pre-verbal focus position. In the case of complex verbs, the participants might have used the post-verbal position of the particle as a clue that the subject was focused. This explanation, though simple, is not very probable. For one thing, the findings have been stable across a large number of follow-up experiments not reported here. In addition, there is a very clear variation between the different lexicalizations within the simple verb and complex verb groups. This would not be expected if the effect was merely a recognition failure, since acoustic recognition of the focused expression should not be dependent on particular verbs. Given these findings, we assume that verbal prefixes are not only a diagnostic for pre-verbal focus in Hungarian but also play a role in the exhaustive interpretation of immediately pre-verbal focus.

This observation has major methodological implications on the empirical study of Hungarian focus. Usually, the post-verbal appearance of verbal particles has been used as a diagnostic for the presence of an immediately pre-verbal focus, and allowed for corpus studies in written texts. However, if our reasoning above is correct, then the presence of verbal particles itself plays a role in the exhaustiveness of immediately pre-verbal focus in Hungarian, and hence cannot be used as a simple diagnostic tool. In addition, of course, the new data raise the theoretical question: how does the presence or absence of verbal particles interact with focus interpretation and affect exhaustification?

\section{Discussion}

The results of the two experiments do not pattern with the predictions of the standard claim that immediately pre-verbal focus in Hungarian is semantically exhaustive, i.e. that the exhaustiveness inference is part of the truth conditions of sentences containing such foci. We consider this to be strong evidence against the claim. For this reason we conclude that the exhaustiveness effect associated with immediately pre-verbal focus in Hungarian is not semantic. Yet, the experimental data also show that immediately pre-verbal focus in Hungarian is interpreted more exhaustively than prosodic focus in German, hence linguistic theory needs to account for the stronger pragmatic tendency to exhaustify pre-verbal focus in Hungarian.

We have suggested that the immediately pre-verbal position in Hungarian is grammatically constrained to be a question-answering constituent and that in Hungarian there is no other unmarked question-answering position. Hence, even isolated from any context, pre-verbal foci in Hungarian will be interpreted as answering an accommodated wh-question. We assume a pragmatic tendency to interpret answers as adequate for the conversational goals at hand, which will often imply the answers are complete, and hence exhaustive.

In some languages, like English or German, prosodic prominence can be triggered by a variety factors, and being the answering constituent to a question is only one of them. This predicts (i) that in isolation Hungarian immediately preverbal foci are more exhaustive than German foci, but also (ii) that in German ex- 
haustiveness increases if the sentence is clearly an answer to a wh-question, whereas for Hungarian such an effect is not predicted.

While this correctly predicts that immediately pre-verbal focus in Hungarian is generally interpreted more exhaustively than prosodic focus in German, the analysis is also compatible with data that were puzzling for previous analyses such as the example (13) repeated here as (18). While for analyses which assume that immediately pre-verbal focus involves semantic exhaustiveness, the fact that the focus appears in the scope of többek között ('among others') is impossible to explain, for our analysis this is a simple instance of a non-exhaustive, but nevertheless direct answer to a wh-question.

$$
\begin{aligned}
& \text { Péter többek között MARIT csókolta meg. } \\
& \text { Peter among others Mary.ACC kissed PRF } \\
& \text { 'Peter kissed MARY, among others }
\end{aligned}
$$

We hypothesize that the enhanced exhaustiveness effect associated with the presence of verbal particles may be directly connected to the fact that verbal particles are themselves immediately pre-verbal in their default position. In this position, the semantic contribution of the particle is to signal that the event introduced by the verb is complete. We suggest that when the particle is post-verbal as in (2), repeated here as (19), the completion is de-emphasized. There is then a stronger tendency to view the completed action as previously salient than for comparable sentences lacking any verbal particle. If our analysis is on the right lines, then it would be expected that many speakers interpret (19) in isolation as answering the question in (19a) as opposed to the question in (19b). So (19) answers a very specific question about a salient situation, while comparable sentences lacking a completive particle are less specific, quantifying indefinitely over situations, and are less likely to be interpreted exhaustively.

(19) Péter MARIT csókolta meg.

Peter PRF-kissed Mary.ACC

'Peter kissed Mary.'

a. Who is the kissee in $s$ ?

(where $\mathrm{s}$ is a unique salient situation in which Peter performs a kissing act)

b. Who is the kissee in any situation of Peter kissing someone?

Thus while we analyze all exhaustivity effects in Hungarian pragmatically, aspectual particles can lead to a pragmatic double whammy, with two separate effects leading to increased exhaustivity.

\section{Summary}

Our experimental results show that when experimental subjects hear an utterance with an immediately pre-verbal focus for which the standard exhaustivity inference 
fails, they do not respond as if the utterance were false. Rather, subjects either accept the utterance, or behave as would be expected if they took the utterance to be pragmatically inappropriate. We conclude that the exhaustivity effects associated with this position in Hungarian are pragmatic, and hypothesize that they occur because the position is grammatically constrained to contain the answering constituent to the question under discussion. The pragmatic tendency to interpret cooperative answers to questions as complete then explains the exhaustivity effects.

We also found some very suggestive results as regards differences in exhaustivity effects when an explicit question is present, and differences in exhaustivity effects when the sentence contains an aspectual particle. We have suggested explanations for these further effects. If our hypotheses are in the right ballpark, then the explanation can only be fleshed out in terms of a detailed theory of the pragmatics of questions and answers. And even if we are wrong about this, what is clear is that neither of these effects can be explained in terms of any prior theory of the meaning and function of Hungarian pre-verbal focus. It is clear that further theoretical work is called for. But we hope it is also clear that experimental work on this topic pays dividends, in helping us to obtain a far more refined understanding of the data than is possible using a more traditional linguistic methodology that involves a rather coarse-grained partitioning of sentences into good and bad.

Szabolcsi (1981), É. Kiss (1998, 2007), Horváth (2006) analyzed Hungarian immediately pre-verbal focus position as being semantically exhaustive. In fact, the exhaustivity is not semantic, though they were right in observing that something special is going on, since Hungarian immediately pre-verbal focus position is indeed different as regards exhaustivity than e.g. German prosodic focus. Perhaps our experiments are best understood not as saying No! to the claims of these prior scholars, or indeed Yes!, but rather Yes, but....

\section{References}

Beaver, David and Brady Clark: 2008, Sense and Sensitivity. Blackwell, Oxford.

É. Kiss, Katalin: 1998, 'Identificational Focus versus Information Focus', Language 74, 245-273.

É. Kiss, Katalin: 2007, 'Topic and Focus: Two Structural Positions Associated with Logical Functions in the Left Periphery of the Hungarian Sentence', in M. Krifka and C. Féry (eds.), Working Papers of the SFB632 (ISIS, No. 6, 69-82. Universität Potstdam.

Horn, Laurence R.: 1985, 'Metalinguistic negation and pragmatic ambiguity', Language 61, 121-174.

Horváth, Júlia: 2006, 'Separating Focus Movement from Focus', in V. K. et al (ed.), Clever and Right: a Festschrift for Joe Emonds. Mouton de Gruyter, Berlin.

Kratzer, Angelika: 2009, 'Pragmatic Strengthening for Free', in Talk given at $D G F S$. Osnabrück.

Onea, Edgar: 2007, 'Exhaustivity, Focus and Incorporation in Hungarian', in M. 
Aloni, P. Dekker, and F. Roelofsen (eds.), Proceedings of the Sixteenth Amsterdam Colloquium, 169-174. ILLC/Department of Philosopty University of Amsterdam, Amsterdam.

Roberts, Craige: 1996, 'Information Structure in Discourse. Towards an Integrated Formal Theory of Pragmatics.', in J.-H. Yoon and A. Kathol (eds.), Ohio State University [=OSU] Working Papers in Linguistics, Vol. 49, 91-136.

Szabolcsi, Anna: 1981, 'Compositionality in Focus', Acta Linguistica Societatis Linguistice Europaeae 141-162.

Wedgwood, Daniel: 2005, Shifting the Focus: From Static Structures to the Dynamics of Interpretation, Current Research in the Semantics Pragmatics Interface. Elsevier, Oxford.

Wedgwood, Daniel, Gergely Pethő, and Ronnie Cann: 2006, 'Hungarian 'Focus Position' and English it-clefts: the Semantic Underspecification of 'Focus' Readings'. Unpublished ms., University of Edinburgh. 